Doi: $10.24234 / \mathrm{se} .2020 .2 .2 .231$

\title{
PSYCHOLOGICAL BARRIERS OF INCLUSIVE INTERACTION
}

\author{
AUTHORS' DATA: \\ Yelena Slusareva, $\mathrm{PhD}$ in Psychology, Associate Professor \\ Chair of Special and Clinical Psychology, Stavropol State Pedagogical Institute, Russia \\ University lecturer \\ Contacts: slusareva2005@yandex.ru
}

\begin{abstract}
The "inclusive" populations contain a great difference in sensory, cognitive and physical user capabilities, particularly when non-age-related impairments are taken into account. While this population is growing, the most productive research and strategy sector is unavoidably shrinking in part to that growth.

The article presents an analysis of the psychological barriers that arise in the process of inclusive interaction. The mechanisms of barriers' genesis are substantiated: objective barriers determined by the presence of health limitations (biosensor disturbances) and subjective ones caused by the intrapersonal characteristics of the partners in the interaction.

Keywords: interaction, inclusive interaction, psycho-cognitive, emotional, communicative barriers, interdisciplinary approach.
\end{abstract}

\section{INTRODUCTION}

At present, the problem of interaction is interdisciplinary and is of interest to specialists from various scientific fields such as philosophy, psychology and pedagogy.

In the philosophical dictionary, interaction is interpreted as a process of mutual influence, any connection and relationship between material objects and phenomena (Suvorov, 2018).

The pedagogical science says that the interaction of a person with other people is a special type of communication, a relationship that involves mutual affections of the participants, crossinfluences and changes. In the pedagogical plan, "interaction" determines the very existence of teaching and educational processes, it is associated with goals and content, methods and forms 
of pedagogical activity, motives of behavior and driving forces of the pedagogical process (Kan- Kalik,1981; Markova, 1993).

In psychology communication, which is used to characterize the whole diversity of natural and social phenomena, is often considered as a synonym for interaction. Communication is a complex multidimensional process of establishing and developing contacts between people, generated by the needs for co-operation and including the exchange of information, the development of a unified strategy for interaction, perception and understanding of a partner. Interaction is presented as a process of direct impact of objects (subjects) on each other, generating their mutual conditionalism (dependence) and connection (Lomov, 1981; Suvorov, 2018).

Since in the process of communication various kinds of interactions are realized and various relationships are formed, it can be represented as a subject - subject relations, where each participant of communication is active. Activity is measured by the initiative a person influences a partner while communicating, how participants in communication interact with each other and how the opposite side perceives the partner's actions.

Activity involves the use of different means of communication and the willingness of an interaction partner to build behavioral strategies in accordance with the reaction of the partner.

But how to act in cases where there are objective obstacles to communication, associated with the presence of a person's health limitations and, as a result, limited communication opportunities (in the presence of sensory, biosensor, mental, etc. disturbances). In this case, we are talking about inclusive interaction - the full-scale entry in equal relations of persons with conditionally normative evolvement and persons with disabilities.

The purpose of this article is to systematize the idea of an inclusive interaction barriers (people with biosensor disturbances (deaf-blind adults) and sighted and hearing volunteers included in the guiding process of deaf-blind).

The problem of interaction between persons with biosensor disturbances (simultaneous hearing and vision impairments) was studied by native and foreign scientists (Suvorov, 2018; Sirotkin, 2006; Salomatina, 2005). As Sirotkin (2006) notes, the peculiarity of people with double sensory impairment is not only the complex of visual and hearing defects, but in many cases problems with speech. Because of these barriers which are difficult to define in the interaction, 
caused by the unsuitability of traditional means of transmitting information (oral speech, listening to it, interpreting expressive signs based on vision - gestures, facial expressions, body language).

While arguing this point Suvorov writes: "... I have formulated the thesis that I (like so many other deaf-blind - probably, and not only deaf-blind), in many cases have the mechanisms of communication impaired, but they simply have not been established, have not been formed during the whole life. The point is not that we once knew how to communicate normally, but then for some reason we "forgot how", but that we were never able to or were able to in a limited sphere, outside of which normal mechanisms had never formed so either an abnormal, pathological mechanism works, or neither works, we are just in complete abashment" (Suvorov, 2018 p.57).

Analysis of studies undertook by Basilova (2003), Yermakova (2013), Sirotkina (2006) and Suvorova (2018) made it possible to classify the barriers of deaf-blind and sighted and hearing interaction due to the following reasons which are introduced in Table 1:

\section{Table 1.}

Barriers of deaf-blind and hearing interaction presented in groups

\begin{tabular}{|l|l|}
\hline The first group & $\begin{array}{l}\text { Psycho-cognitive barrier - the inability to transfer the existing } \\
\text { knowledge about the psychological characteristics of deaf-blind people in } \\
\text { the practical aspect of interaction with them, and a barrier of } \\
\text { incompetence associated with ignorance of means of information } \\
\text { transmission to a deaf-blind partner (daktiology and sign language } \\
\text { inefficiency) }\end{array}$ \\
\hline The second group & $\begin{array}{l}\text { Emotional barriers - the barrier of disbelief in their own strength; barrier } \\
\text { of mental tension (anxiety, inability to initiate contact with a deaf and } \\
\text { blind interlocutor); barrier of fear; barrier of shame and guilt arising from } \\
\text { the awkwardness of oneself we had assigned. }\end{array}$ \\
\hline The third group & $\begin{array}{l}\text { Communication barriers, which exist as: } \\
\text { a semantic barrier - occurs as a result of misunderstanding of the } \\
\text { situation of interaction: a deaf -blind person may not understand the } \\
\text { sense of the conversation, a joke, which may lead to a violation of } \\
\text { behavior strategies; }\end{array}$ \\
\hline
\end{tabular}




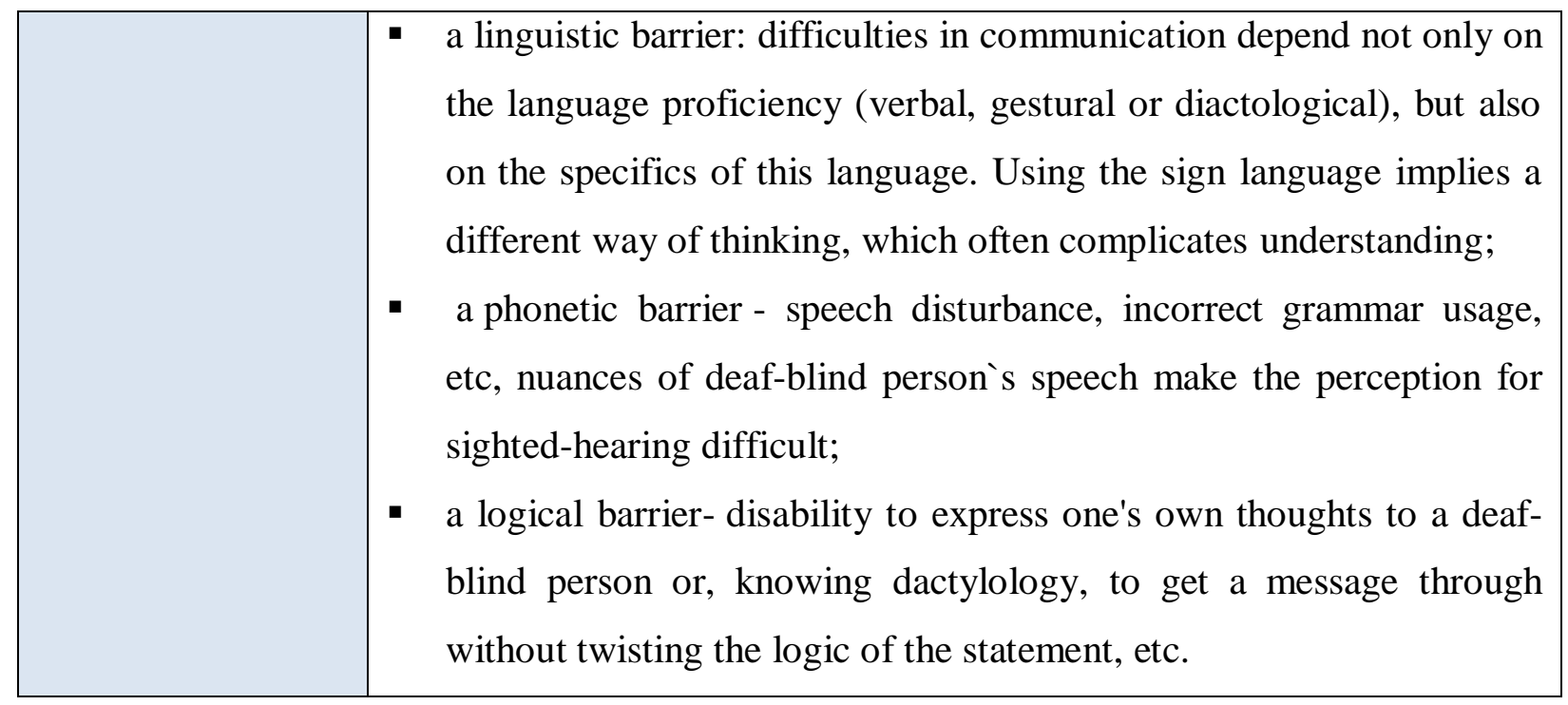

It should be noted that this group of barriers is equally pronounced in both deaf-blind and interlocutors without any impairments.

More often deaf-blind person has this phenomena appearing as the barrier of personal self-conception, which expresses itself in the fear blaming, fear of being misunderstood, feeling of uneasiness, uselessness, their own importunity. According to Suvorov, in the vast majority of cases when there is a snag in communication, it is difficult to get out softly from a clearly bad situation, which author called a game, and therefore, talking nonsense, which is bitterly regretted by him for a very long time (Suvorov, 2018, p.58).

These sighted-hearing volunteers have shown these barriers to a greater extent as a barrier to disbelief in themselves, a barrier of fear and communication with deaf-blind people, a barrier of shame and guilt arising from embarrassment for oneself or another. Citing one of the volunteers participating in activities with deaf-blind children for several years, it is important to show that interaction is not an easy one to build and work on: "I am so ashamed that after working for many years with children with health limitations, I still do not know how to interact with them."

Thus, barriers may occur on the individual (subjective barriers caused by the peculiarities of interacting subjects) and functional (objective barriers caused by the complex structure of developmental disorder) levels. They can be both of objective (at the level of architectural, informational accessibility) and subjective (psychological unwillingness of participants in educational relations to interact, emotional barriers of fear and embarrassment, etc.) nature. 


\section{REFERENCE LIST}

1. Abulkhanova, K., A. (1999). Psychology and consciousness of personality. - M: Voronezh

2. Basilova, T., A. (2002). Problimy psikhicheskogo zdorovya lic, poteryavshikh slukh i zrenie v podrostkovom vozraste // Defektologiya, № 4.- s. 23-28.

3. Yermakova, E., A. (2013). Theoretical analysis of the causes and mechanisms of difficulties in social interaction among people with double sensory impairment // Scientific- methodical electronic journal "Concept", Vol. 3. p. 2481-2485.

4. Kan - Kalik, V., A. (1981). To a teacher about pedagogical communication /V.A. KanKalik - M.

5. Lomov, B., F. (1981). The problem of communication in psychology. - M.

6. Markova, A., K. (1993). Psychology of teacher's work. - M.

7. Salomatina, I., V. (2005). Semya slepoglukhogo cheloveka o svoikh problemakh // Defektologiya, №1.- s. 35-41.

8. Sirotkin, S., A. (2006). Ethics of relationships and communication with the deaf-blind. M.

9. Suvorov, A., V. (2018). Meeting of the universes or deaf-blind aliens in the world of sighted and hearing. - M. 